\title{
Identification of Imitation Gold and Silver as Metallic Pigments Used in an Illuminated Persian Manuscript by SEM-EDS and Optical Microscope
}

\author{
M.J. Mousavi, *H. Ahmadi, ** A. Abed-Esfahani, ${ }^{* * *}$ M. Mortazavi, **** M. Karbasi***** \\ * Faculty of Conservation, Art University of Isfahan, PO Box 1744, Isfahan, Iran \\ ** Faculty of Conservation, Art University of Isfahan, PO Box 1744, Isfahan, Iran \\ *** Basic Sciences Deparment, Islamic Azad University-Khorasgan Branch, PO Box 81595-158, Isfahan, Iran \\ **** Faculty of Conservation, Art University of Isfahan, PO Box 1744, Isfahan, Iran \\ ***** Materials Engineering Faculty, Isfahan University of Technology, PO Box 84156-83111, Isfahan, Iran
}

Scientific investigations of historical manuscripts are very important for precise recognition the materials used in the illumination of manuscripts. Two metallic pigments including golden and silvery particles were identified on a Qajar $\left(18^{\text {th }}-19^{\text {th }}\right.$ century) illuminated Persian manuscript belonging to Soltanabad museum of Arak (Iran) that named Bayaz (FIG.1). There pigments have been discolored in most of the pages. Investigations carried out with Digital Microscope for preliminary identification of metallic pigments and size of particles and SEM-EDS instrument revealed original composition of the pigments and their degradation.

Silver particles were in the size range of $0.3-1.1 \mathrm{~mm}$. The sheets of the manuscript by reason of applying fine particles of silver known as kaghadh-e afshan; Kaghadh-e afshan was paper that was flecked with gold or silver dust [1]. Although silver is a white metal, on pigments it is often tarnished (FIG.2). This has long been a problem, as silver ranks as one of the more sensitive materials regarding exposure to atmospheric contaminates [2]. SEM-EDS analysis revealed silver sulfide as degradation products (TABLE1).

Digital microscope images showed golden particles in green color and also demonstrated discoloration of golden color to greenish hue. Scanning electron images revealed that the green coloration is actually the result of a marked degradation process (FIG.3) that has altered the original composition of the pigment which contained an alloy of copper, zinc and tin. Results of SEM-EDS analysis showed that the composition of pigment is close to brass (TABLE2).

Similar pigments were occasionally identified by Guineau et al. in a $9^{\text {th }}$ century manuscript composed in Fulda, Germany, and by Fuchs et al. in some $11^{\text {th }}$ and $12^{\text {th }}$ century manuscripts. Indeed, the relative rarity of brass-like ink may be due to the lack of proper analytical determinations in cases where the presence of gold ink had been taken for granted and not really investigated; Thus suggesting that the so-called Kupferfra $\beta$ phenomenon investigated by Banik et al. had occurred. Kupferfra $\beta$, though, being due to $\mathrm{Cu}$ ions, must not be regarded as the cause but as a consequence of the alteration of metallic copper [3]. Besides the destructive action of green pigments, copper alloy - usually brass - that have been used to imitate gilding, similarly destroy paper objects [4].

\section{References}

[1] W. Floor, Traditional Crafts in Qajar Iran (1800-1925), Mazda, California, 2003.

[2] J. Winter, East Asian Paintings, Archetype, London, 2008.

[3] M. Aceto et al., J. Raman Spectrosc.41(2010) 1434.

[4] G. Banik, Rest.10 (1989) 61. 
TABLE1. Results of SEM-EDS elemental analyses obtained for silver particles on paper

\begin{tabular}{lcc}
\hline Eltements & $\begin{array}{l}\text { Untarnished } \\
\text { particle }\end{array}$ & $\begin{array}{l}\text { Tarnished } \\
\text { partcle }\end{array}$ \\
\hline $\mathrm{Si}$ & - & $1.50 \%$ \\
$\mathrm{~S}$ & - & $10.74 \%$ \\
$\mathrm{Cu}$ & $2.37 \%$ & $4.00 \%$ \\
$\mathrm{Ag}$ & $90.90 \%$ & $83.76 \%$ \\
$\mathrm{Au}$ & $3.09 \%$ & - \\
$\mathrm{Pb}$ & $3.64 \%$ & - \\
& & \\
\hline \hline Total & $100.00(\mathrm{wt} . \%)$ & $100.00(\mathrm{wt} . \%)$ \\
\hline
\end{tabular}

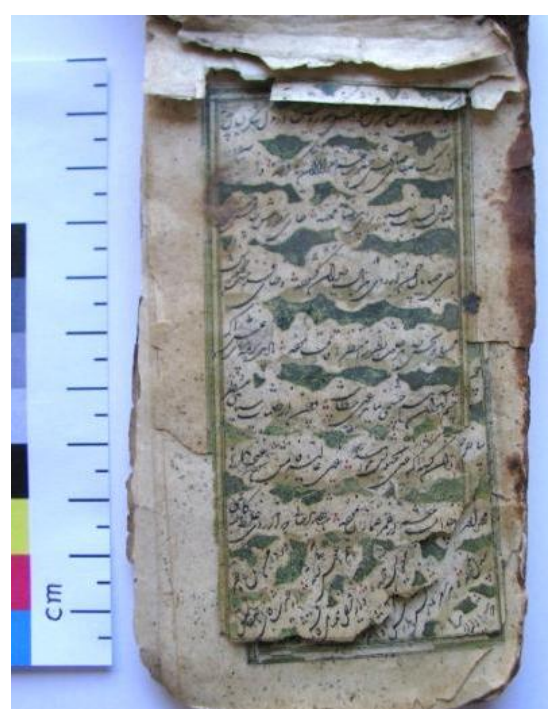

TABLE2. Results of SEM-EDS elemental analyses obtained for imitate gold pigments with SEM-EDS analysis

\begin{tabular}{lcc}
\hline Eltements & Analysis 1 & Analysis 2 \\
\hline & & \\
$\mathrm{Cu}$ & $81.88 \%$ & $86.47 \%$ \\
$\mathrm{Zn}$ & $10.52 \%$ & $7.29 \%$ \\
$\mathrm{Sn}$ & $7.60 \%$ & $6.24 \%$ \\
& & \\
\hline \hline Total & $100.00($ wt. $\%)$ & $100.00($ wt. $\%)$ \\
\hline
\end{tabular}

FIG. 1 First page of manuscript (Bayaz): degradation of imitate gold pigment

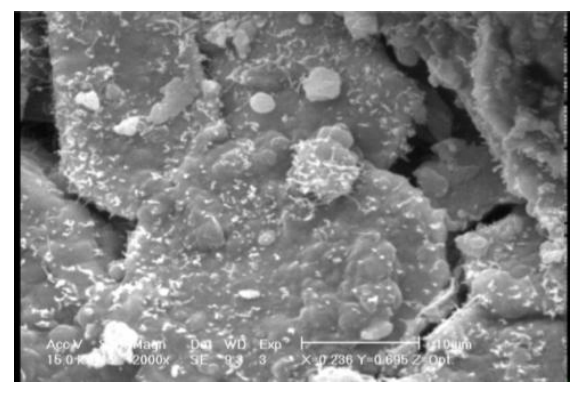

FIG. 3 SEM image of degraded imitate gold pigment

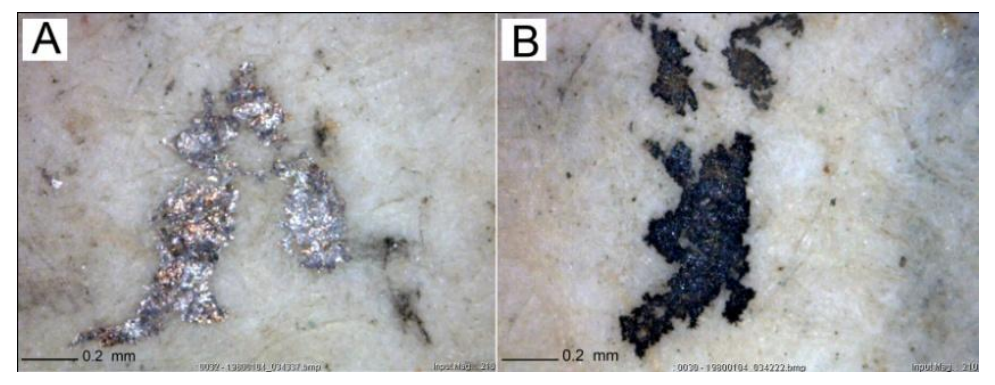

FIG. 2 Optical microscope images of silver sprinkle on paper:

A. Untarnished particle; B. Tarnished particle 